\title{
Logistische Regelkreise und Frauenkarrieren
}

Seinen traditionellen Jahresempfang beging der Landesverband Niedersachsen am 16. Februar 2012 im Leibnizhaus in Hannover. Als Aufsichtsratsmitglied der Deutschen Post AG hielt den Festvortrag Frau Prof. Dr.-Ing. Katja Windt von der Jacobs University Bremen gGmbH (Professor of Global Production Logistics). Ihr Vortrag „Der logistische Regelkreis zum Umgang mit Störgrößen auf dem Karriereweg von Frauen" begann dabei als Nachhilfestunde in dem für die meisten völlig unbekannten Kosmos der Mess- und Regeltechnik. Vor zahlreichen Mitgliedern des Verbands und ihren Gästen, darunter auch Mitglieder des Landtags, zog die Festrednerin dann allerding spannende Parallelen zu Frauenkarrieren. Anschließend lud die Regionalgruppe Hannover bei Sekt und Brezeln zum Netzwerken.

Auf dem Foto sind Brigitte Meyer-Wehage als Landesvorsitzende und die Festrednerin, Prof. Dr.-Ing. Katja Windt, zu sehen. (Birgit Kemming)

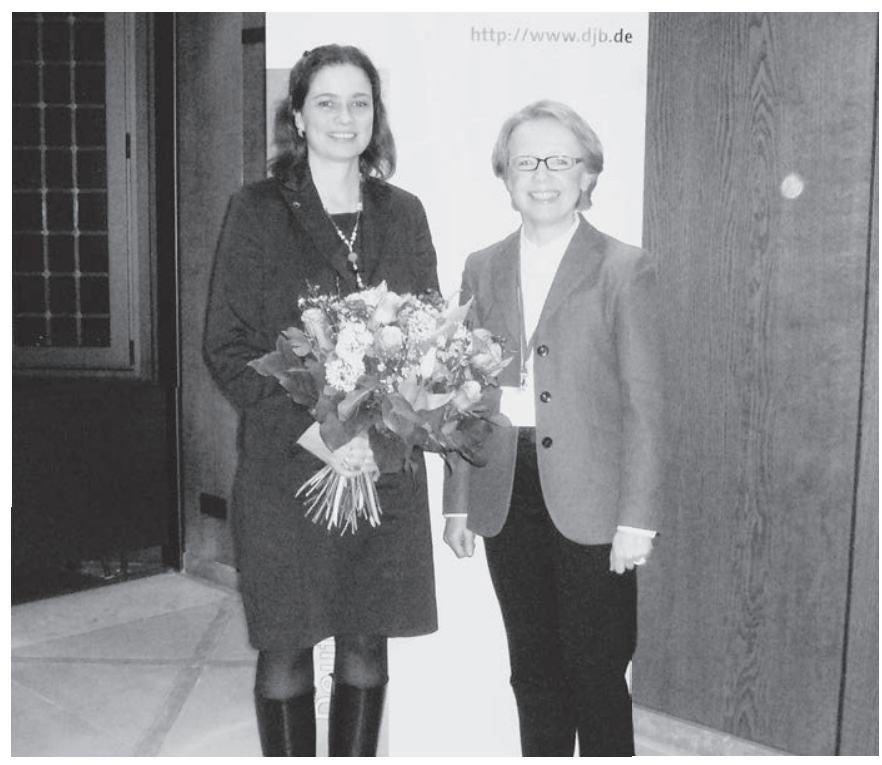

\section{Helga-Stödter-Preis der Handelskammer Hamburg für Mixed Leadership}

\section{Preisverleihung am 21. März 2012 in Hamburg}

\section{Juliane Freifrau von Friesen \\ Senatorin a.D., Berlin}

Es wäre für sie sicher das schönste Geschenk zu ihrem 90. Geburtstag gewesen. Leider konnte die 2011 verstorbene Dr. Helga Stödter die erstmalige Verleihung des nach ihr benannten Preises nicht mehr selbst erleben. Dafür waren ihre drei Töchter und die meisten ihrer 14 Enkelinnen und Enkel der Einladung in die Handelskammer Hamburg zusammen mit vielen Frauen und Männern gefolgt. Sie alle wollten eine Pionierin in Sachen Gleichberechtigung und Gleichstellung ehren, für deren Person und Engagement der Präses der Kammer, Fritz Horst Melsheimer, hoch anerkennende Worte fand. Mit dem Helga-Stödter-Preis werde zusammen mit der Helga-Stödter-Stiftung ein Zeichen gesetzt. Die Wirtschaft brauche mehr Frauen in Führungspositionen, so Melsheimer. Auf wenig Zustimmung stieß er allerdings mit seiner darauffolgenden Feststellung, die Quote sei der falsche Ansatz, sie überzeuge nicht und erzeuge obendrein Widerstand.

Dem widersprach Maria von Welser heftig. Sie sei sicher, dass Helga Stödter heute für die Quote wäre. Die Laudatorin des Abends, bekannt als „Mona Lisa“-Moderatorin im ZDF und Direktorin im NDR, bekam für ihre deutlichen Worte großen Applaus.

Es folgte die Übergabe der Preise für vorbildliche Gleichstellungspolitik und -praxis an die Bode Chemie $\mathrm{GmbH}$, ver- treten durch ihren Geschäftsführer Roland Knieler, und die Euler Hermes Versicherungs-AG, für die Vorstandsmitglied Hans Janus gekommen war. Sowohl das erstgenannte Hamburger Unternehmen mit 310 Mitarbeiter/inne/n als auch das Großunternehmen mit einer Belegschaft von 1570 Mitarbeiter/inne/n in der Hansestadt hatten die Weichen in Richtung Frauen gestellt. Auf den Anteil von 58 Prozent Frauen in Führungsfunktionen (Bode) als auch auf 60 Prozent weiblichen Führungsnachwuchs (Euler Hermes) waren beide Unternehmensvertreter sichtlich stolz.

Was im Anschluss an die Preisverleihung folgte, war ein mit Verve und geradezu körperlichem Einsatz vorgetragenes Bekenntnis zur Quote von Thomas Sattelberger. Er wolle die Quote nicht, so der Personalvorstand der Deutschen Telekom, aber ohne sie gehe es - jedenfalls in einem Großunternehmen - nicht. Er wetterte gegen Symbolpolitik ohne Systematik, die überwiegend betrieben werde, und geißelte solche Kollegen, die Frauen- und Gleichstellungspolitik vielerorts zum Hinterhofthema ihrer Personalpolitik degradiert hätten. Mixed Leadership müsse es auf allen Ebenen der Unternehmen geben und für die Aufsichtsratsgremien sei die Quote die ultima ratio. Aufsichtsräte seien die Stellhebel für die Vorstandsbesetzung. Über sie könne und müsse der dringend notwendige Wandel in Gang gesetzt werden. Hier säßen die Mächtigen, die die bislang geschlossenen Systeme öffnen und die allenthalben eingezogenen Glasdecken zerschlagen könnten. 
Für dieses klare Bekenntnis erhielt Sattelberger donnernden Applaus, unter anderem von der früheren Hamburger und Berliner Justizsenatorin Dr. Lore Maria Peschel-Gutzeit, Ehrenpräsidentin des djb, der Medienanwältin und ebenfalls djb-Ehrenpräsidentin Renate Damm sowie der Präsidentin der Initiative „Frauen in die Aufsichtsräte“ (FidAR), Monika Schulz-Strelow, und der Direktorin des Deutschen Instituts für Wirtschaftsforschung (DIW) Berlin, Dr. Elke Holst. Sie alle sind seit vielen Jahren überzeugte Verfechterinnen der Quote.
Brachte der scheidende Konzernpersonalmanager - ihm folgt eine Frau im Telekom-Vorstand - das feministische Blut quasi in Wallung, berührten die abschließenden Worte der Enkelin von Helga Stödter, Henriette Böckel, die Herzen. Ihrer Danksagung war anzumerken, wie sehr sie ihre Großmutter bewunderte und es bleibt zu wünschen, dass sie so engagiert und erfolgreich durchs Leben gehen wird wie diese.

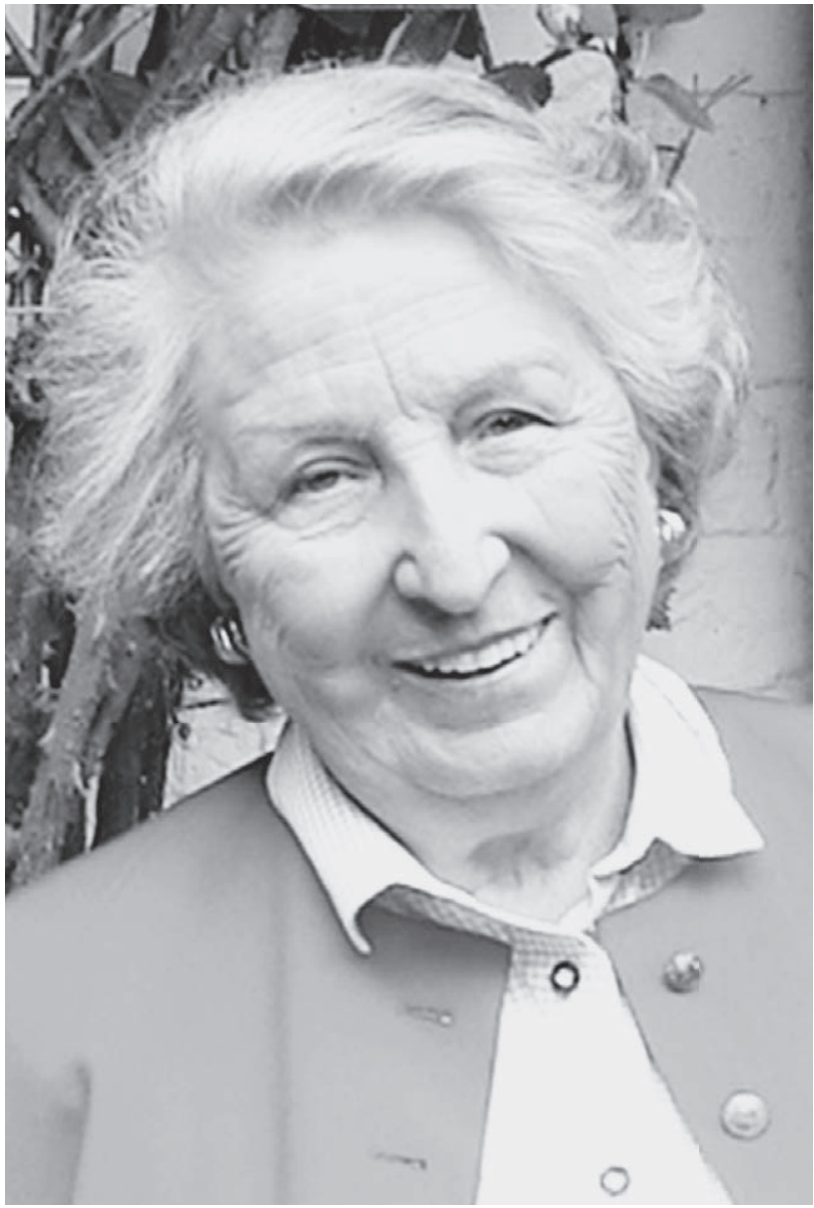

Dr. Helga Stödter (9. März 1922 - 21. Mai 2011) studierte an den Universitäten Berlin und Tübingen Auslandswissenschaften, Zeitungswissenschaften und Volkswirtschaft, legte 1942 ihr Diplom-Volkswirtexamen in Tübingen ab und promovierte 1943 zum Dr. rer. pol. 1944 bestand sie ihre Erste juristische Staatsprüfung und war bis zum Ende des Krieges Universitätshilfsassistentin am Auslandswissenschaftlichen Institut der Universität Tübingen. Nach Kriegsende wurde sie im Mai 1945 provisorisch als Strafverteidigerin vor französischen Militärgerichten zugelassen und 1946 durch das damalige Justizministerium Württemberg/ Hohenzollern als „Offizialverteidigerin“ vor dem Obersten Französischen Militärgericht für die sogenannten „Kriegsverbrecher-Prozesse“ in Rastatt einberufen. Sie war die erste und blieb, bis sie 1950 aufhörte, die einzige Frau in dieser Funktion. Nebenher setzte sie ihre Referendarausbildung fort und bestand im Mai 1949 ihr Zweites juristisches Staatsexamen. 1951 wurde sie als Anwältin in Stuttgart zugelassen.

1952 trat sie als Anwärterin für den Höheren Konsularischen und Diplomatischen Dienst in das Auswärtige Amt ein, bestand im Frühjahr 1953 das entsprechende Examen und wurde an die Deutsche Botschaft nach London versetzt. Sie war dort in der Rechts- und Konsularabteilung und in der politischen Abteilung tätig, zuletzt als Legationsrätin. 1961 kam sie wegen Heirat und Geburt ihrer Kinder nach Deutschland zurück und wurde als Rechtsanwältin am Land- und Oberlandesgericht in Hamburg zugelassen. Sie beschäftigte sich insbesondere mit Gesellschaftsrecht und Familienrecht.

Sie übernahm zahlreiche ehrenamtliche Aufgaben, hielt unzählige Vorträge und publizierte. Unter vielem anderem war sie seit Anfang der Fünfzigerjahre Mitglied des djb und arbeitete in Kommissionen - insbesondere 1966 in der djbKommission zur Ausarbeitung einer Stellungnahme zu dem Referentenentwurf eines Unehelichengesetzes des BMJ und von 1967 bis 1975 im Bundesvorstand mit. Sie vertrat den djb bei Konferenzen der FIDA und war von 1972 bis 1982 Vorsitzende der Untergruppe Hamburg. 2005 verlieh ihr der djb die Ehrennadel für langjährige Mitgliedschaft und Mitarbeit (6o Jahre).

Für die Höchstdauer von 12 Jahren war sie von 1972 bis 1984 Mitglied der Ständigen Deputation des Deutschen Juristentages. Von 1971 bis 1973 war sie Vizepräsidentin, von 1973 bis 1975 Präsidentin der Dachorganisation westlich orientierter nationaler Juristinnenverbände FIDA ( Federación Internacional De Abogadas ). In dieser Eigenschaft organisierte und leitete sie einen Internationalen Juristinnenkongress 1975 (Jahr der Frau) in Hamburg. Sie war Mitbegründerin des EWMD (European Women's Management Development Network) und war von 1984 bis 1986 dessen erste Präsidentin. Im Oktober 1986 erhielt sie das Bundesverdienstkreuz am Bande. 1988 errichtete sie die „Helga-Stödter-Stiftung - Frauen für Führungspositionen“, deren Ziel es ist, Frauen in Berufs- und Karrierefragen zu informieren, zu beraten, zu ermutigen und zu unterstützen. Quelle: http:// www.helga-stoedter-stiftung.de/stiftung/stifterin/) (AG) 